\title{
Pulmonary hypertension produced in rats by ingestion of Crotalaria spectabilis seeds
}

\author{
J. MICHAEL KAY, PETER HARRIS, AND DONALD HEATH
}

From the Departments of Pathology and Medicine, University of Birmingham

\begin{abstract}
The oral administration of Crotalaria spectabilis seeds to young rats induces pulmonary hypertension in them associated with right ventricular hypertrophy and an increase in the medial thickness of the pulmonary trunk and muscular pulmonary arteries. This appears to be the first direct demonstration that the oral administration of an agent may bring about pulmonary hypertension.
\end{abstract}

Young rats fed on a diet which contains Crotalaria spectabilis seeds or the pyrrolizidine alkaloid monocrotaline die from congestive heart failure within 36 to 60 days. At necropsy they are found to have ascites, pleural effusions, and cardiac enlargement due to right ventricular hypertrophy (Turner and Lalich, 1965 ; Kay and Heath, 1966). Microscopic examination reveals an increase in the medial thickness of the pulmonary trunk (Heath and Kay, 1967) and small pulmonary arteries (Turner and Lalich, 1965 ; Kay and Heath, 1966), and in about one-third of the animals an acute necrotizing pulmonary arteritis (Lalich and Merkow, 1961 ; Kay and Heath, 1966). Since similar changes in the heart weight and pulmonary vasculature in man are well known to be associated with severe pulmonary hypertension (Wagenvoort, Heath, and Edwards, 1964) we thought it likely that the pulmonary vascular lesions produced in rats by Crotalaria spectabilis seeds are also associated with an elevation of the pulmonary artery pressure. It has never been shown that the oral administration of any agent can produce pulmonary hypertension, so we considered that its direct demonstration in rats fed with such seeds would be of considerable significance. Accordingly we measured right atrial and ventricular pressures in a group of rats maintained on a diet containing Crotalaria spectabilis seeds and compared these with values obtained from a group of control rats. In addition, we investigated the relation between right ventricular systolic pressure on the one hand, and the medial thickness of the small pulmonary arteries and the pulmonary trunk and the right ventricular weight on the other.

\section{METHODS}

Thirteen female weanling Wistar albino rats (initialo weight 65 to $79 \mathrm{~g}$.) were individually marked and? divided into two groups comprising five test animals and eight controls. They were weighed at the outset? of the experiment and three times weekly until itso conclusion. The test animals received a diet of $\mathcal{Q}$ powdered Thomson rat cubes to which had been $\overrightarrow{\hat{O}}$ added finely ground Crotalaria spectabilis seeds to 3 give a concentration of $0 \cdot 1 \%$. Control animals were? given unadulterated powdered rat cubes. All animalso had free access to food and water.

The intracardiac pressures were determined by introducing a fine metal cannula connected to a capacitance manometer into the right jugular vein $\times$ under light ether anaesthesia and advancing it along the superior vena cava into the right atrium and then. into the right ventricle. It proved impossible too measure the pulmonary artery pressure directly, but for the purposes of this experiment the right ventricu-o lar systolic pressure was regarded as being equivalent to the pulmonary artery systolic pressure, there beingo no evidence of pulmonary valve disease. The mean right atrial pressure was calculated from planimetry of the pressure recordings through at least two respiratory cycles. The right ventricular systolic pressure was calculated from the mean height of thew systolic peaks of the pressure recording over at leasto two respiratory cycles.

After pressure readings had been taken the rats were killed and necropsy was performed immediately. Thes? thoracic viscera were removed en bloc and the lungs were distended through the trachea with $4 \%$ formaldehyde in normal saline until their pleural surfaces were $\stackrel{\mathbb{D}}{\mathbb{D}}$ smooth. The thoracic contents were then immersed in? the same solution until fixation was complete. The $\mathbb{\perp}$ pulmonary trunk and ascending aorta were dissectedo free from the heart and embedded in paraffin wax. 
Transverse sections of both vessels were cut at $5 \mu$ thickness and stained by the Lawson modification of the Weigert-Sheridan method for elastic fibres counterstained with Van Gieson's stain for collagen and muscle. In each case the medial thickness of the vessel was measured as the distance in $\mu$ between the internal and external elastic laminae. Ten measurements of the medial thickness were made on each vessel and from these one mean medial thickness was calculated. The mean medial thickness of the pulmonary trunk was expressed as a ratio of the mean medial thickness of the aorta.

The heart was opened and blood and excess fixative were removed. The free wall of the right ventricle was dissected from the remainder of the heart and weighed. The right ventricular weight was expressed as a ratio of the total body weight of the rat and, to avoid tedious repetition of decimal places, this ratio was multiplied by a factor of $10^{4}$.

One block of tissue was taken from the left lung and the superior, middle, inferior, and median lobes of the right lung and embedded in paraffin wax. Sections were cut at $5 \mu$ thickness and stained with Ehrlich's haematoxylin and aqueous eosin and by the elastic-Van Gieson stain as described above. Measurements of the external diameter and average thickness of the media of the pulmonary arteries were made in all the test and control animals. Only vessels that wero virtually circular in transverse section were measured. The diameter was taken as the mean of two measurements, at right angles to each other, of the distance between diametrically opposite points on the external elastic lamina. The medial thickness was estimated as the mean of four measurements taken at approximately equally spaced points around the vessel wall. From these data the thickness of the media was expressed as a percentage of the external diameter of the vessel. A value for the average percentage medial thickness in each animal was obtained by totalling all the mean percentage medial thicknesses and dividing the sum by the number of vessels examined.

\section{RESULTS}

Intracardiac pressure measurements (Table) were made on the control rats between the thirty-seventh and forty-fourth days of the experiment. The mean right atrial pressure was obtained in seven of these animals and the range was -1 to $4 \mathrm{~mm}$. Hg. The right ventricular systolic pressure was measured in the eight control rats and found to lie between 22 and $36 \mathrm{~mm}$. $\mathrm{Hg}$. The mean right atrial pressure was measured in four of the test rats after they had been on the diet containing Crotalaria spectabilis seeds for 37 or 38 days; it ranged between 8 and $10 \mathrm{~mm}$. $\mathrm{Hg}$. The right ventricular systolic pressure was obtained in all five of the test rats and was found to range between 62 and $112 \mathrm{~mm}$. Hg.
T A B L E

RIGHT VENTRICULAR SYSTOLIC AND MEAN RIGHT ATRIAL BLOOD PRESSURES IN THE EIGHT CONTROL AND FIVE TEST RATS

\begin{tabular}{c|c|c}
\hline \multirow{2}{*}{ Rat } & \multicolumn{2}{|c}{ Mean Pressure (mm. Hg) } \\
\cline { 2 - 3 } & R.V.S. & R.A. \\
\hline C1 & 31 & 4 \\
C2 & 29 & 1 \\
C3 & 36 & 3 \\
C4 & 27 & 4 \\
C5 & 22 & $\ldots$ \\
C6 & 31 & -1 \\
C8 & 27 & 2 \\
\hline T1 & 31 & 3 \\
T2 & 112 & 9 \\
T3 & 62 & 8 \\
T5 & 82 & 10 \\
& 77 & 9
\end{tabular}

C $=$ control rat $; \mathbf{T}=$ test rat R.V.S. $=$ right ventricular systolic pressure; R.A. = mean right atrial pressure

The ratio of the weight of the right ventricle to the total body weight multiplied by a factor of $10^{4}$ in the control rats lay between 3.5 and 5.2 . In the test rats this ratio ranged between 6.6 and 20.8 (Fig. 1).

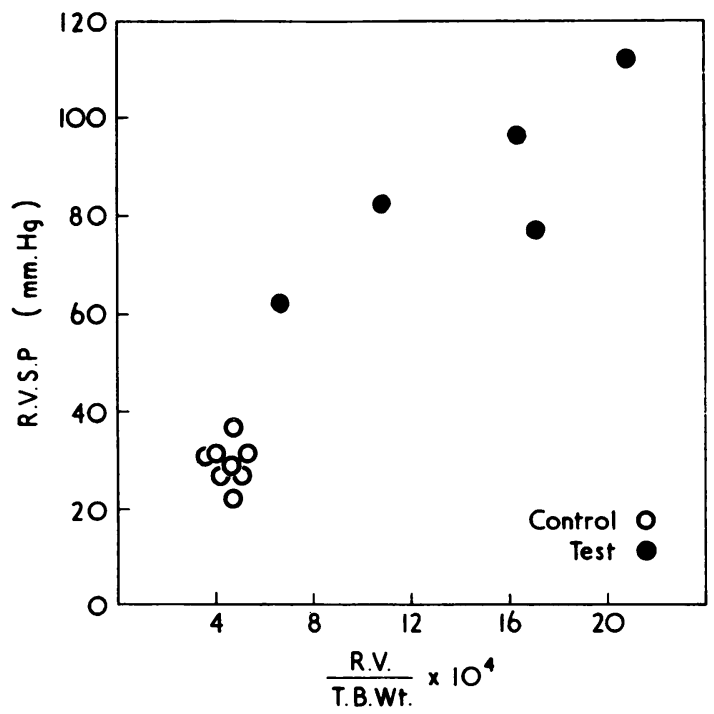

FIG. 1. Relation between the right ventricular systolic pressure and the weight of the right ventricle expressed as a ratio of the total body weight.

In the control rats the ratio of the medial thickness of the pulmonary trunk to the medial thickness of the aorta ranged between 0.29 and $0 \cdot 36$. In the test rats this ratio ranged between 0.90 and $1 \cdot 10$ (Fig. 2).

The average medial thickness of the muscular 


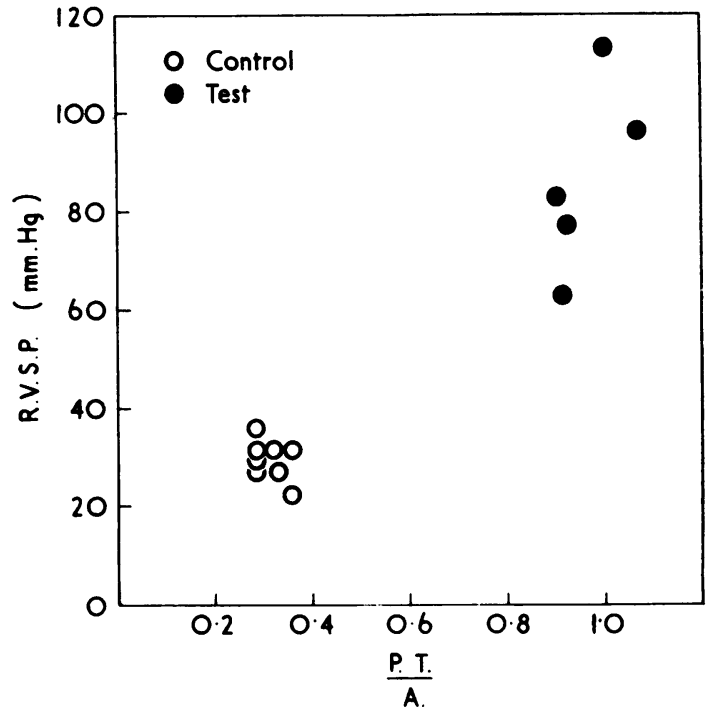

FIG. 2. Relation between the right ventricular systolic pressure and the medial thickness of the pulmonary trunk expressed as a ratio of the medial thickness of the aorta.

pulmonary arteries in the control rats ranged between $4 \%$ and $6 \%$ of their external diameter. The average medial thickness of these vessels in the test rats was between $8 \%$ and $16 \%$ of their external diameter (Fig. 3).

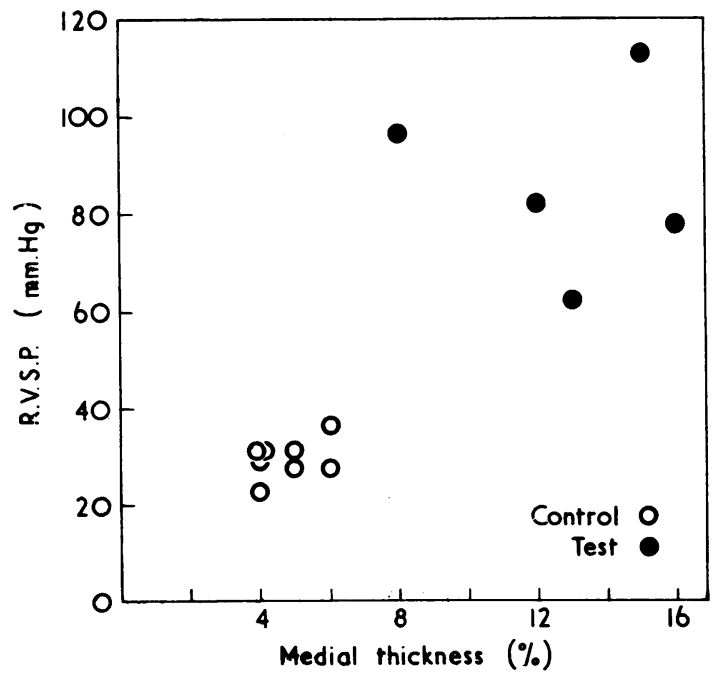

FIG. 3. Relation between the right ventricular systolic pressure and the average medial thickness of the small pulmonary arteries expressed as a percentage of their external diameter.
No effusions were present in the body cavities at necropsy. Microscopic examination of the lungs showed no evidence of pulmonary arteritis.

\section{DISCUSSION}

This experiment demonstrates that the prolonged oral administration of Crotalaria spectabilis seeds to rats induces pulmonary hypertension in them, and that this is associated with right ventricular hypertrophy and an increase in the medial thickness of the pulmonary trunk and the small pulmonary arteries. So far as we are aware, this is the first occasion on which it has been shown that the oral administration of a substance may bring about pulmonary hypertension. This finding raises the possibility that some cases of primary pul- monary hypertension encountered in clinical practice may have a dietary basis.

The mechanism by which Crotalaria spectabilis seeds produce pulmonary hypertension is not yet clear. It has been shown that the active principle of the seeds is the pyrrolizidine alkaloid monocrotaline (Lalich and Ehrhart, 1962). So far, our attempts to produce an immediate rise in right ventricular pressure in rats by the administration of a solution of monocrotaline hydrochloride by the intraperitoneal and intramuscular routes have been unsuccessful. The delayed action of ingested Crotalaria spectabilis seeds may be due to the monocrotaline being metabolically converted into a toxic substance in the liver. A similar mechanism has been suggested by Barnes, Magee, and Schoental (1964) to explain the selective toxic action of the related pyrrolizidine alkaloid fulvine on the cells of the liver and lung. It has been shown that there is an increase in the number of mast cells in the lungs of rats to which monocrotaline has been administered (Takeoka, Angevine, and Lalich, 1962). The mast cells of rats contain 5-hydroxytryptamine, and Turner and Lalich (1965) have suggested that this substance may play some part in the genesis of the pulmon- of ary vascular lesions produced by monocrotaline.

An electron microscopic study of the pulmonary $\mathrm{C}^{-}$ arteries of rats poisoned with monocrotaline ad- $O$ ministered by both the oral and intraperitoneal routes has been reported by Merkow and Kleiner- $\frac{C}{0}$ man (1966). They describe an electron-dense $\stackrel{?}{?}$ amorphous material which occurred beneath the 0 endothelial cells, between and around smooth $\overrightarrow{0}$ muscle cells, surrounding the internal and external $\stackrel{\mathbb{Q}}{\circ}$ elastic laminae, and extending into the inter- $\mathbb{D}$ cellular regions of the adventitia. They suggest that this material is derived from protein which has 
diffused through from the lumen of the vessel. Hayashi and Lalich (1966) have reported the occurrence of thickening of the pulmonary arteries and right ventricular hypertrophy in rats 20 days after a single subcutaneous injection of monocrotaline. Sonnad, Valdivia, and Hayashi (1966) have also studied the early electron microscopic changes in the lungs of rats following subcutaneous injections of monocrotaline. They have described narrowing of alveolar capillaries and aggregation of platelets in their lumina. Focal alterations in pulmonary capillary permeability were demonstrated using Thorotrast. These authors propose that partial capillary obstruction is responsible for the development of pulmonary hypertension and right ventricular hypertrophy.

We gratefully acknowledge a gift of Crotalaria spectabilis seeds from Dr. Averill A. Liebow, of Yale University.

A table showing heart and body weights in the control and test rats may be obtained on request from the authors.

\section{REFERENCES}

Barnes, J. M., Magee, P. N., and Schoental, R. (1964). Lesions in the lungs and livers of rats poisoned with the pyrrolizidine alkaloid fulvine and its N-oxide. J. Path. Bact., 88, 521.

Hayashi, Y., and Lalich, J. J. (1966). Production of cor pulmonale in rats by single injection of monocrotaline. Amer. J. Path., 48, 35a.

Heath, D., and Kay, J. M. (1967). The medial thickness of the pulmonary trunk in rats with cor pulmonale induced by ingestion of Crotalaria spectabilis seeds. Cardiovasc. Res., 1, 74.

Kay, J. M., and Heath, D. (1966). Observations on the pulmonary arteries and heart weight of rats fed on Crotalaria spectabilis seeds. J. Path. Bact., in press.

Lalich, J. J., and Ehrhart, L. A. (1962). Monocrotaline-induced pulmonary arteritis in rats. $J$. Atheroscler. Res., 2, 482.

— and Merkow, L. (1961). Pulmonary arteritis produced in rats by feeding Crotalaria spectabilis. Lab. Invest., 10, 744.

Merkow, L., and Kleinerman, J. (1966). An electron microscopic study of pulmonary vasculitis induced by monocrotaline. Ibid., 15, 547 .

Sonnad, J., Valdivia, E., and Hayashi, Y. (1966). Electron microscopy of the early pulmonary lesions produced by monocrotaline. Amer. J. Path., 48, 35a.

Takeoka, O., Angevine, D. M., and Lalich, J. J. (1962). Stimulation of mast cells in rats fed various chemicals. Ibid., 40, 545.

Turner, J. H., and Lalich, J. J. (1965). Experimental cor pulmonale in the rat. Arch. Path., 79, 409.

Wagenvoort, C. A., Heath, D., and Edwards, J. E. (1964). The Pathology of the Pulmonary Vasculature, p. 146. Charkes C. Thomas, Springfield, IHlinois. 